\title{
Mapping of inner and outer celestial bodies using new global and local topographic data derived from photogrammetric image processing
}

\author{
I.P. Karachevtseva ${ }^{a^{*}}$, A.A. Kokhanov ${ }^{\text {a }}$, J.F. Rodionova ${ }^{\text {a,b }}$, A.Yu. Zharkova ${ }^{\text {a, }}$, M.S. Lazareva ${ }^{\text {a }}$ \\ ${ }^{a}$ Moscow State University of Geodesy and Cartography (MIIGAiK), MIIGAiK Extraterrestrial laboratory (MExLab), \\ 105064. Gorokhovsky per., Moscow, Russia \\ i_karachevtseva@miigaik.ru \\ ${ }^{\mathrm{b}}$ Sternberg State Astronomical Institute, 1198993, Moscow, Russia
}

Commission IV, WG IV/8

KEY WORDS: Planetary cartography, DEM, geomorphology study, Phobos, the Moon, Mercury, Ganymede and Enceladus

\begin{abstract}
New estimation of fundamental geodetic parameters and global and local topography of planets and satellites provide basic coordinate systems for mapping as well as opportunities for studies of processes on their surfaces. The main targets of our study are Europa, Ganymede, Calisto and Io (satellites of Jupiter), Enceladus (a satellite of Saturn), terrestrial planetary bodies, including Mercury, the Moon and Phobos, one of the Martian satellites. In particular, based on new global shape models derived from three-dimensional control point networks and processing of high-resolution stereo images, we have carried out studies of topography and morphology. As a visual representation of the results, various planetary maps with different scale and thematic direction were created. For example, for Phobos we have produced a new atlas with 43 maps, as well as various wall maps (different from the maps in the atlas by their format and design): basemap, topography and geomorphological maps. In addition, we compiled geomorphologic maps of Ganymede on local level, and a global hypsometric Enceladus map. Mercury's topography was represented as a hypsometric globe for the first time. Mapping of the Moon was carried out using new images with super resolution (0.5-1 $\mathrm{m} /$ pixel) for activity regions of the first Soviet planetary rovers (Lunokhod-1 and -2). New results of planetary mapping have been demonstrated to the scientific community at planetary map exhibitions (Planetary Maps Exhibitions, 2015), organized by MExLab team in frame of the International Map Year, which is celebrated in 2015-2016. Cartographic products have multipurpose applications: for example, the Mercury globe is popular for teaching and public outreach, the maps like those for the Moon and Phobos provide cartographic support for Solar system exploration.
\end{abstract}

\section{INTRODUCTION}

Planetary mapping in Russia has been initiated during the early ambitious Soviet space program (Shevchenko et al., 2016). As the Russian Space Research program is gaining momentum again, the interest in planetary science in Russia is growing. To present the results of new planetary research and to support the planning of future missions we have prepared various online and printed maps of planets and their satellites. For example, for Phobos we produced an Atlas (Karachevtseva et al., 2015a) as well as digital thematic cartographic products for selection of future landing sites (Karachevtseva et al., 2015b).

Mapping of planetary surface is a research process developed for going beyond the standard image analysis, so many maps are created as results of various studies. To determine global relief features as well as topography of a small region cartographers created maps using DEMs and images with difference resolutions as main basis for mapping, for example: global geological map of Ganymede (Patterson et al., 2010; Collins et.al., 2013); map of Apollo 17 landing site (Haase et al., 2012); Phobos and Deimos cartography (Wählisch et al., 2014).

Unlike Earth mapping, the implementation of Internet access and GIS technologies that provide many benefits for mapping were started only recently in planetary cartography (Hare et al., 2003), and have been intensively used since 2010 (Nass and van Gasselt, 2010). Modern planetary cartography integrates the different scientific and technologic tasks: to establish the coordinate system and provide basic maps derived from photogrammetric image processing (global and local DEMs, orthomosaics); to study planetary surface feature characteristics using GIS-tools; to use new possibilities to publish various types of planetary cartography products such as digital maps (http://astrogeology.usgs.gov/), online maps (http://bit.ly/Lunohod_1), as well as access to spatial data via a geoportal, for example, Planetary Data system (http://wms.lroc.asu.edu/lroc) or Planetary geoportal of the MIIGAiK Extraterrestrial laboratory (http://cartsrv.mexlab.ru/geoportal/\#body=moon\&proj=sc\&loc= $\% 280.3515625 \% 2 \mathrm{C} 43.9453125 \% 29$ \&zoom=2\&lang=en).

Our workflow for mapping of the Solar system planets and their satellites combines all steps (Karachevtseva et al., 2015). Planetary mapping is based on results of photogrammetric image processing and spatial analysis of remote sensing data from different missions: archive images from Galileo (19942003), Voyager (1979-1981), Mars Global Surveyor (20012007), MESSENGER (2011-2015), as well as images from ongoing missions - Lunar and Reconnaissance Orbiter, Mars Express, Mars Reconnaissance Orbiter, and Cassini.

\section{MAPPING}

\subsection{Phobos}

The small Martian moon Phobos with its irregular shape has been intensively studied in the frame of Mars Express mission. Based on a recently updated three-dimensional control point network (Oberst et al., 2014), a new shape model and base orthomosaic were formed. We have developed a web system to storage and to access the result of the studies (Karachevtseva et al., 2014). For management and unified organization of created spatial data we have designed a special logical model, which described the relationships between planetary features and their representation. To describe the various classes of spatial objects 
the model comprises systematic or proprietary information that consists of definitions, rules and relationships of data sets, ensuring various functions, such as support for topologies and domains. It provided good benefits to study surface detail as well as to compile maps for the Phobos atlas (Karachevtseva et al., 2015a) that includes base maps and thematic maps at global and regional level, and some local maps based on high resolution images.

In the frame of atlas preparation detailed geomorphological studies of the Phobos surface have been carried out, especially studies of the unique grooves, the origin of which remains unclear. Several sets of the grooves crossing each other and forming large networks which not found on any other small stony worlds. The GIS analysis of grooves was updated recently and a new groove catalog was established. Detailed measurements of the length, width and orientation for all identified grooves can contribute to the understanding of their nature (Lorenz et al., 2016).

To present the result of this study we have suggested new symbols for planetary mapping, based on new classifications of the various types of grooves. Building on the results of analysis a new geomorphological map has been created (Karachevtseva et al., 2015a). To update a series of maps of terrestrial planets (Shingareva et al., 2005) a new wall map of Phobos grooves has been compiled, additionally (Fig.1). The map represents the spatial distributions of detected grooves based on its classifications by morphological types and orientation. The borders of identified morphological regions are shown, and geographical characteristics of the regions are briefly described.

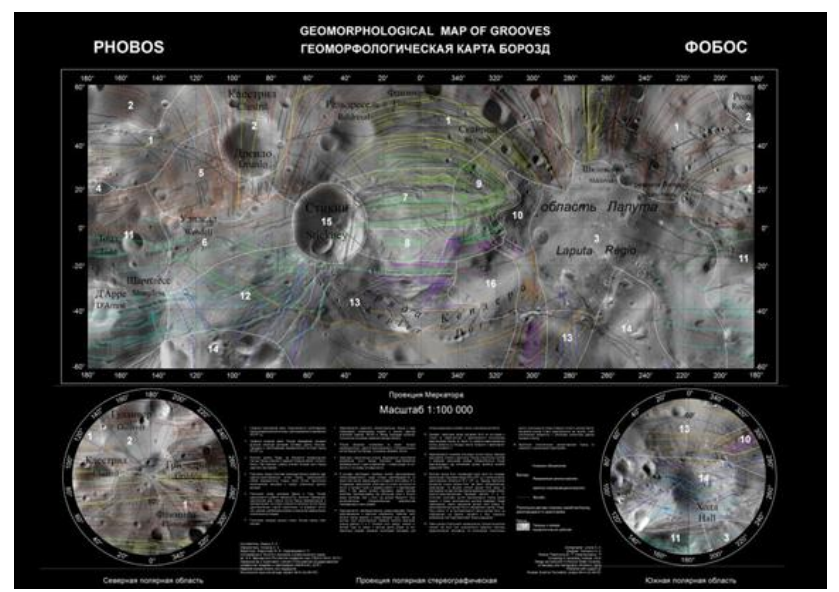

Figure 1. A layout of a new geomorphological wall map of Phobos (size A1) based on detailed study of grooves

\subsection{The Moon}

The Lunar Reconnaissance Orbiter (LRO) was launched on June 18, 2009 and provided data with highest resolution (some images were obtained from orbits as low as $21 \mathrm{~km}$ above the mean surface). Past lunar landing sites such as Apollo 17 (Haase et al., 2012) as well as Luna-17 (Lunokhod-1) and Luna21 (Lunokhod-2) working areas have been LRO priority targets. We focused on the Lunokhods' traverses (Karachevtseva et al., 2013) using results of stereo processing (Zubarev, et al., 2016, this issue). The vertical accuracy of the DEMs depends on image resolutions, illumination conditions as well as on size of study areas - Lunokhod-1 0.1-0.5 m: $10 \mathrm{~km}^{2}$; Lunokhod-2: 2-3 $\mathrm{m}: \sim 200 \mathrm{~km}^{2}$. Using high resolution DEMs and GIS tools we reconstruct the rover traverses, which gives us new insights into Soviet mission achievements.
To present the results of study the maps of Mare Imbrium area and part of Le Monnier crater (the activity regions of the Soviet Lunokhods) were compiled. On the hypsometric map of the Lunokhod-1 track (Fig.2a) craters near the rover traverse were named after Russian men's names, improved by IAU (http://planetarynames.wr.usgs.gov/Page/MOON/target), given also in English; for craters at Lunokhod-2 studied area we suggested Russian women's names and used them on the map in unofficial way (Fig.2b).

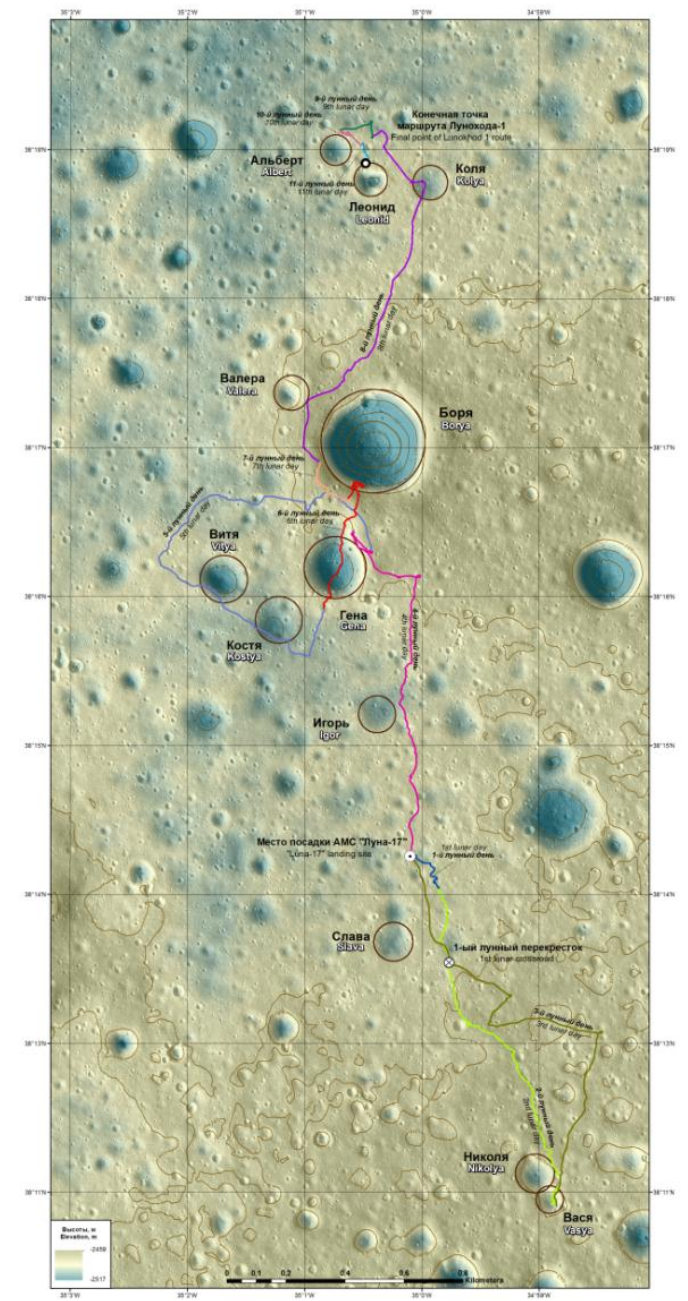

a)

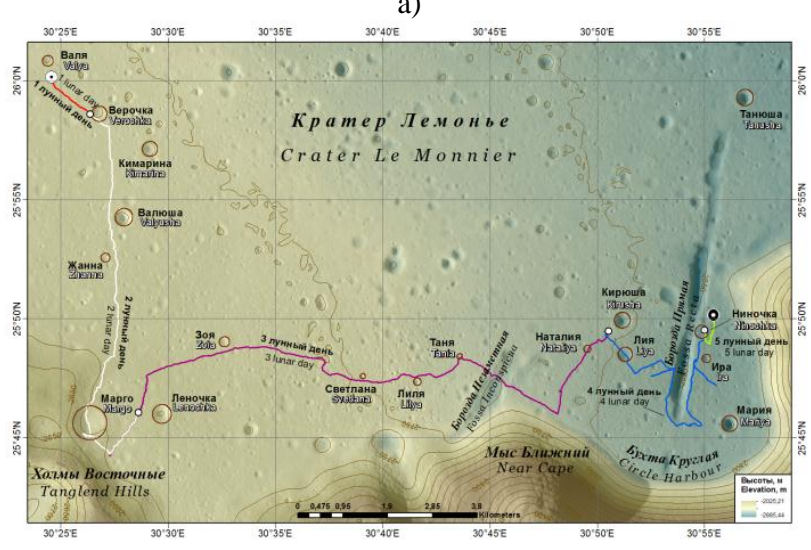

b)

Figure 2. A layout maps of rover traverses based on high resolution DEMs from LRO NAC stereo processing: a) Luna-17 landing area (Lunokhod-1);2) Luna-21 landing area (Lunokhod-2) 
Both Lunokhod maps are compiled in A3 format and gave a fresh look at the history of the Soviet lunar exploration program. Study of these regions at local level using LRO Narrow angle camera (LRO NAC) stereo images provides the basis for further study of lunar sub-polar areas. Usually the slopes can be measured with the DEM produced from image stereo pairs. However, for the lunar polar regions these direct measurements are not possible, because the sun is always very low, and many steep slopes are hidden in shadows. Comparing modeled slopes and shadows based on LRO NAC DEM for Lunokhod's area the estimation of slope in the Moon sub-polar area that planning as landing site for future Russian lunar mission has been done (Abdrakhimov et al., 2015).

\subsection{Mercury}

With the coming European mission BepiColombo the interest in Mercury cartography is increasing. To support new mission we have studied Mercury's surface at various levels of detail. We have collected different topography data sets (Fig.3), including new MESSENGER data:

DEMs (http://ode.rsl.wustl.edu/mercury/index.aspx) from data obtained by MESSENGER laser altimetry (MLA) (http://www.messenger-education.org/instruments/mla.php):

- covering latitudes from $55^{\circ} \mathrm{N}$ to $90^{\circ} \mathrm{N}(500 \mathrm{~m} / \mathrm{pixel})$;

- covering all the northern hemisphere, including small part of southern from $4^{\circ} \mathrm{S}$ to $90^{\circ} \mathrm{N}(1000 \mathrm{~m} /$ pixel $)$.

DEMs (http://europlanet.dlr.de/node/index.php?id=534) from stereo images obtained by MDIS - Mercury Dual Imaging System, Wide Angle Camera, WAC) (Hawkins et al., 2007) that cover the following areas:

- $65^{\circ} \mathrm{N}-11^{\circ} \mathrm{S}, 97^{\circ} \mathrm{E}-192^{\circ} \mathrm{E} ; 66^{\circ} \mathrm{N}-8^{\circ} \mathrm{S}, 279^{\circ} \mathrm{E}-359^{\circ} \mathrm{E} ; 65^{\circ} \mathrm{N}-$ $54^{\circ} \mathrm{S}, 58^{\circ} \mathrm{E}-87^{\circ} \mathrm{E}(1000 \mathrm{~m} / \mathrm{pixel})$.

Also DEMs (http://europlanet.dlr.de/node/index.php?id=524) obtained by Mariner 10 via orbital stereo-mapping, that cover parts of Mercury's surface $\left(50^{\circ} \mathrm{N}-90^{\circ} \mathrm{N} ; 5^{\circ} \mathrm{N}-65^{\circ} \mathrm{S}, 200^{\circ} \mathrm{E}-0^{\circ} \mathrm{E}\right.$, $2000 \mathrm{~m} / \mathrm{pixel}$ ) are available. In addition, a new global DEM (resolution $22000 \mathrm{~m} /$ pixel) derived from limb observations by the MESSENGER Wide Angle Camera has been produced recently (Elgner et al., 2014).

Our analysis of various topographic information shows a good correlation between global DEMs from limb measurements and DEMs derived from MLA data, as well as between DEMs based on Mariner-10 data, whereas heights from stereo-processing of first MDIS images obtained from flyby orbits do not correlate with topography mentioned above. Due with our tasks of cartography entire Mercury we used global DEM for new mapping.

We applied the global DEM derived from limb measurements for hypsometric mapping based on result of analysis of Mercurian multi-ring basins and plains. The new maps (Fig.4), compiled in azimuthal equidistant projection, showing a global view of this closest planet to the Sun, were used for producing the first hypsometric Mercury globe. Also with new high resolution DEMs (50-200 m/pixel) developed from images obtained by the MESSENGER Narrow Angle Camera (NAC) we have analysed small craters and have shown that the regolith on Mercury is significantly thicker than on the Moon (Zharkova et al., 2015).

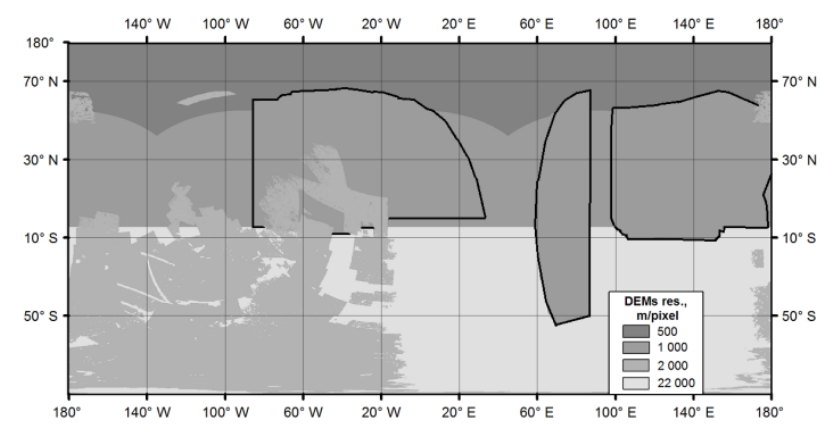

Figure 3. Coverage of Mercury by currently available DEMs

Based on surface studies and newest results of stereo-processing of MESSENGER images obtained by MDIS (WAC and NAC) we are going to produce a new Mercury wall map to update the Terrestrial planets map series. Small interesting features of the Mercurian relief, for example, flat-floored craters and hollows, will be presented for selected study areas at large scale. In maps of global coverage, main relief features of the planet will be demonstrated.

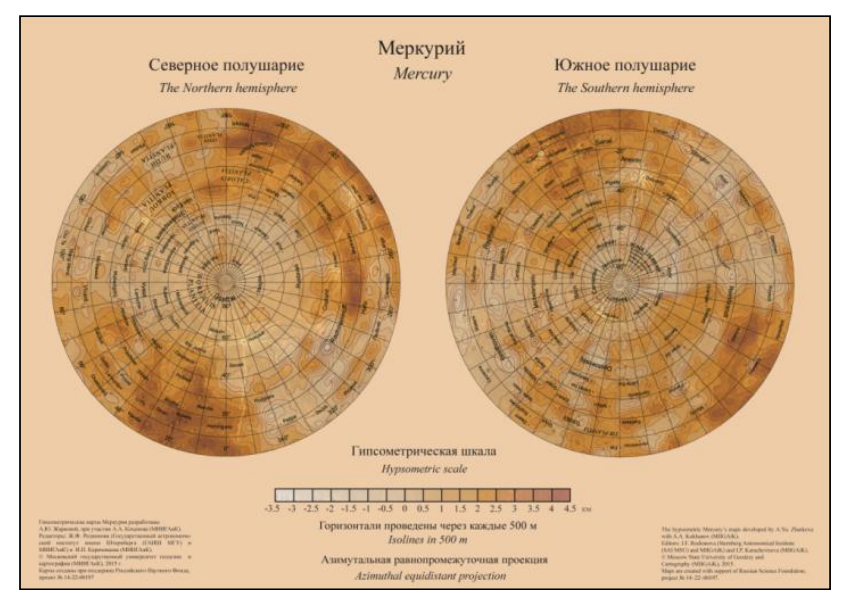

Figure 4. Pamphlet for the Mercury Globe, accompanied by a description of generic hypsometric maps.

\subsection{Ganymede and other Galilean moons}

Ganymede, a satellite of Jupiter, is the largest moon in the Solar System. The relief modeling of some Ganymede's areas by newly identified stereo images, previously not used, is done based on a new 3D-control point network (Zubarev et al., 2015). New DEMs provided an opportunity for geomorphological research at level of great detail: preliminary results show, for example, that small craters of Ganymede are shallower than their lunar and martian counterparts of the same size. To demonstrate the results, large-scale geomorphological mapping of Ganymede based on new high resolution DEMs has been carried out (Fig.5). The proposed map legend, which was developed to show the detailed characteristic of Ganymede's landforms will be used for mapping of other Galilean satellites (Europa, Calisto and Io) and for comparative-planetological analysis. A new series of planetary multilingual maps of the outer satellites will be produced, useful for the scientific community, especially for the forthcoming JUICE mission. 


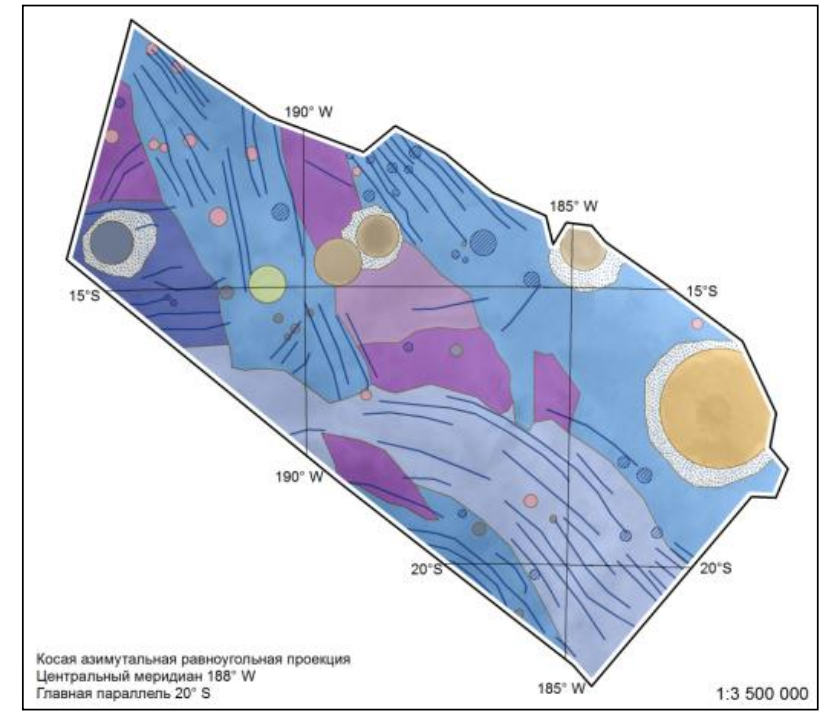

Figure 5. Detailed geomorphological map of Ganymede based on new high resolution DEM

\subsection{Enceladus}

Following previous updates of the Enceladus control point network (Nadezhdina et al., 2012), 197 images obtained by Cassini were processed that formed a new basis for a new global elevation model and orthomosaic of this satellite of Saturn. The orthomosaic has the highest resolution currently available $(100 \mathrm{~m} / \mathrm{pixel})$. Using these data we produced a base map and a hypsometric map of Enceladus (Fig.6) using $500 \mathrm{~m}$ contours, The scale of the map is 1: 2000000 , the projection is simple cylindrical for the central area, and azimuthal equal-area for the sub-polar regions.

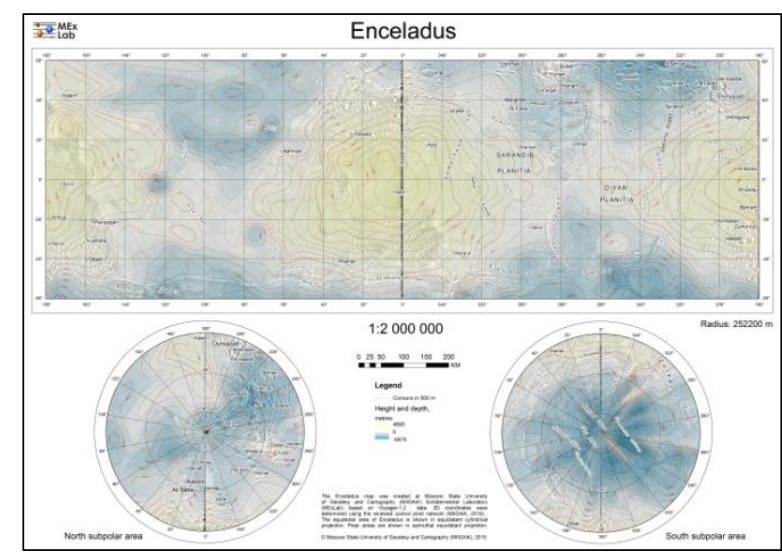

Figure 6. Layout of new global hypsometric map of Enceladus

\section{CONCLUSION}

In frame of International Map Year (http://mapyear.org/ International Map Year, 2015) we have created various planetary maps and other cartographic products (like Phobos atlas or Mercury globe) based on the result of photogrammetry processing of archive and new data obtained by different mission. The spatial measurements in GIS using cartographic methods have been performed. It became a basis for geomorphology analysis of planetary surface, presented in the form of maps. Names of relief features on all maps are given according to the planetary nomenclature (Gazetteer of Planetary Nomenclature, 2015) approved by International Astronomical Union.
As work continues, we are going to update series of multilingual maps of terrestrial planets and we will create new wall maps of Phobos and Mercury using detailed geomorphologic studies of their surfaces. Also to support the idea proposed by Kira Shingareva (Shingareva et al., 2005) we consider creation of a new multilingual map series of outer planet satellites based on our research of the Galilean moons (Io, Europa, Ganymede and Calisto). Cartographic methods can help study unusual surface processes and address key science objectives of future planetary missions, for example, forthcoming European missions JUICE to Jupiter's system and Bepi Colombo to Mercury, Russian missions to the Moon (Luna-Globe) and to Phobos (Boomerang).

\section{ACKNOWLEDGEMENTS}

This work was carried out in MIIGAiK and supported by Russian Science Foundation, project \#14-22-00197.

\section{REFERENCES}

2015. «Gazetteer of Planetary Nomenclature». http://planetarynames.wr.usgs.gov/ (24 Dec. 2015).

2015. «International Map Year». http://mapyear.org/ (24 Dec. 2015).

2015. «Planetary Maps Exhibitions». http://mapyear.org/planetary-maps-exhibitions/ (24 Dec. 2015).

Abdrakhimov A.M., Basilevsky A.T., Ivanov M.A., Kokhanov A.A., Karachevtseva I.P., Head J.W., 2015. Occurrence Probability of Slopes on the Lunar Surface: Estimate by the Shaded Area Percentage in the LROC NAC Images, Solar System Research, V. 49, N. 5, pp. 285-294 (doi: 10.1134/S0038094615050019).

Collins G.C, Patterson G.W., Head J.W., Pappalardo R.T., Prockter L.M, Lucchitta B.K., Kay J.P., 2013. Global Geologic Map of Ganymede: U.S. Geological Survey Scientific Investigations Map 3237, pamphlet 4 p., 1 sheet, scale 1:15,000,000, http://dx.doi.org/10.3133/sim3237.

Elgner S., Stark A., Oberst J., Perry M.E., Zuber M.T, Robinson M.S. Solomon S.C., 2014. Mercury's global shape and topography from MESSENGER limb images, Planetary and Space Science, Vol. 103, 299-308 (doi: 10.1016/j.pss.2014.07.019).

Haase I., Oberst J., Scholten F., Wählisch M., Gläser P., Karachevtseva I., Robinson M. S., 2012. Mapping the Apollo 17 landing site area based on Lunar Reconnaissance Orbiter Camera images and Apollo surface photography, Journal of Geophysical Research, $117, \quad$ E00H20 (doi:10.1029/2011JE003908).

Hare T., Tanaka K., Skinner J., 2003. GIS 101 for Planetary Research, ISPRS WG IV/9: Extraterrestrial Mapping Workshop, Advances in Planetary Technology, LPI, Houston http://webgis.wr.usgs.gov/pigwad/publications/Hare_isprs_mar 03.pdf

Nass A., van Gasselt S., 2011. Planetary mapping-The datamodel's perspective and GIS framework, Planetary and Space Science, Vol. 59, Issue 11-12, pp. 1231-1242 (doi: 10.1016/j.pss.2010.09.012).

Hawkins S.E., Boldt J.D., Darlington E.H., Espiritu R., Gold R.E., Gotwols B., Grey M.P., Hash C.D., Hayes J.R., Jaskulek 
S.E., Kardian C.J., Keller M.R., Malaret E.R., Murchie S.L., Murphy P.K., Peacock K., Prockter L.M., Reiter R.A., Robinson M.S., Schaefer E.D., Shelton R.G., Sterner R.E., Taylor H.W., Watters T.R., Williams B.D., 2007. The Mercury Dual Imaging System on the MESSENGER Spacecraft, Space Science Reviews, Vol. 131, Issue 1-4, 247-338 (doi: 10.1016/j.icarus.2011.07.017).

Karachevtseva I.P., Kokhanov A.A., Rodionova Zh.F., Matveev E.V., Garov A.S., 2015. Modern methodology for planetary mapping // Proceedings of the 1st ICA European Symposium on Cartography, EuroCarto 2015, 10-12 November, 2015, Vienna, Austria http://eurocarto.org/wp-content/uploads/2015/10/37.pdf

Karachevtseva I., Kokhanov A., Rodionova J., Konopikhin A., Zubarev A., Nadezhdina I., Mitrokhina L., Patratiy V., Oberst J., 2015. Development of a new Phobos atlas based on Mars Express image data, Planetary and Space Science, V. 108, pp. 24-30 (doi: 10.1016/j.pss.2014.11.024).

Karachevtseva I.P., Kokhanov A.A., Konopikhin A.A., Nadezhdina I.E., Zubarev A.E., Patratiy V.D., Kozlova N.A., Uchaev D.V., Uchaev Dm.V., Malinnikov V.A., Oberst J., 2015. Cartographic and Geodesic Methods to Characterize the Potential Landing Sites for the Future Russian Missions LunaGlob and Luna-Resurs. Solar System Research, No. 2, Vol. 49, pp. 92-109 (doi:10.1134/S0038094615020021).

Karachevtseva I.P., Oberst J., Zubarev A.E., Nadezhdina I.E., Kokhanov A.A.; Garov A.S., Uchaev D.V., Uchaev Dm.V., Malinnikov V.A., Klimkin N.D., 2014. The Phobos information system, Planetary and Space Science, Vol. 102, pp. $74-85$ (doi: 10.1016/j.pss.2013.12.015).

Karachevtseva I., Oberst J., Scholten F., Konopikhin A., Shingareva K., Cherepanova E., Gusakova E., Haase I., Peters O., Plescia J., Robinson M., 2013. Cartography of the Lunokhod-1 Landing Site and Traverse from LRO Image and Stereo Topographic Data, Planetary and Space Science, Vol.85, p. 175-187 (doi:10.1016/j.pss.2013.06.002).

Lorenz C.A., Kokhanov A.A., Karachevtseva I.P., 2016. Morphological study of Phobos surface and mapping of the grooves, 47th Lunar and Planetary Science Conference http://www.hou.usra.edu/meetings/lpsc2016/pdf/1831.pdf

Nadezhdina I., Patraty V., Shishkina L., Zhukov D., Zubarev A., Karachevtseva I., Oberst J., 2012. Global shape estimates and GIS cartography of Io and Enceladus using new control point network, EGU General Assembly, Vienna, Austria 22-27. 2012. http://adsabs.harvard.edu/abs/2012EGUGA..1411210N

Oberst J., Zubarev A., Nadezhdina, I., Rambaux, N., 2014. Phobos control point network and rotation model, Planetary and Space Science, Vol. 102, p. 45-50 (doi: 10.1016/j.pss.2014.03.006).

Patterson G.W.; Collins G.C.; Head J.W.; Pappalardo R.T.; Prockter L.M.; Lucchitta B.K.; Kay J.P., 2010. Global geological mapping of Ganymede, Icarus, Volume 207, Issue 2, p. 845-867 (doi: 10.1016/j.icarus.2009.11.035)

Shevchenko V., Rodionova Zh., Michael G. Lunar and Planetary Cartography in Russia. 2016, Astrophysics and Space Science Library, Volume 425. ISBN 978-3-319-21038-4. Springer International Publishing Switzerland (doi: 10.1007/978-3-319-21039-1)
Shingareva K.B., Zimbelman J., Buchroithner M.F. and Hargitai H.I., 2005. The Realization of ICA Commission Projects on Planetary Cartography, Cartographica, vol. 40, no. 4 /Winter, 2005 pp. 105-114 (doi: 10.3138/3660-4078-55X13808).

Wählisch M., Stooke P.J., Karachevtseva I.P., Kirk R., Oberst J., Willner K., Nadejdina I.A., Zubarev A.E., Konopikhin A.A., Shingareva K.B., 2014. Phobos and Deimos cartography, Planetary and Space Science, Vol. 102, pp. 60-73 (doi: 10.1016/j.pss.2013.05.012).

Zharkova A.Yu., Kreslavsky M.A., Brusnikin E.S., Zubarev A.E., Karachevtseva I.P., Head III J.W., 2015. Morphometry of Small Flat Floored Craters on Mercury: Implications for Regolith Thickness, American Geophysical Union, San Francisco, December 14-18, 2015. P53A-2099.

Zubarev A., Nadezhdina I., Oberst J., Hussmann H., Stark A., 2015. New Ganymede control point network and global shape model, Planetary and Space Science, V. 117, pp. 246-249 (doi: 10.1016/j.pss.2015.06.022).

Web references

http://mapyear.org/

http://mapyear.org/planetary-maps-exhibitions/

http://planetarynames.wr.usgs.gov/

http://planetarynames.wr.usgs.gov/Page/MOON/target

http://astrogeology.usgs.gov/

http://bit.ly/Lunohod_1

http://wms.lroc.asu.edu/lroc

http://cartsrv.mexlab.ru/geoportal/\#body=moon\&proj=sc\&loc= $\% 280.3515625 \% 2$ C43.9453125\%29\&zoom=2\&lang=en

http://ode.rsl.wustl.edu/mercury/index.aspx

http://www.messenger-education.org/instruments/mla.php

http://europlanet.dlr.de/node/index.php?id=534

http://europlanet.dlr.de/node/index.php?id=524 